\title{
Optics outreach activities with elementary school kids from public education in Mexico
}

P. Viera-González, G. Sánchez-Guerrero, J. RuizMendoza, G. Cárdenas-Ortiz, D. Ceballos-Herrera, et al.

P. Viera-González, G. Sánchez-Guerrero, J. Ruiz-Mendoza, G. CárdenasOrtiz, D. Ceballos-Herrera, R. Selvas-Aguilar, "Optics outreach activities with elementary school kids from public education in Mexico," Proc. SPIE 9188, Optics Education and Outreach III, 91880P (15 September 2014); doi: $10.1117 / 12.2058071$

EDIE Event: SPIE Optical Engineering + Applications, 2014, San Diego, California, United States 


\title{
Optics outreach activities with elementary school kids from public education in Mexico
}

\author{
P. Viera-González, G. Sánchez-Guerrero, J. Ruiz-Mendoza, G. Cárdenas-Ortiz, D. Ceballos-Herrera, \\ R. Selvas-Aguilar
}

Centro de Investigación en Ciencias Físico Matemáticas - Facultad de Ciencias Físico Matemáticas

- Universidad Autónoma de Nuevo León, Av. Universidad S/N Ciudad Universitaria, San Nicolás de los Garza, Nuevo León, México

\begin{abstract}
This work shows the results obtained from the "O4K" Project supported by International Society for Optics and Photonis (SPIE) and the Universidad Autonoma de Nuevo Leon (UANL) through its SPIE Student Chapter and the Dr. Juan Carlos Ruiz-Mendoza, outreach coordinator of the Facultad de Ciencias Fisico Matematicas of the UANL. Undergraduate and graduate students designed Optics representative activities using easy-access materials that allow the interaction of children with optics over the exploration, observation and experimentation, taking as premise that the best way to learn Science is the interaction with it. Several activities were realized through the 2011-2013 events with 1,600 kids with ages from 10 to 12; the results were analyzed using surveys. One of the principal conclusions is that in most of the cases the children changed their opinions about Sciences in a positive way.

Keywords: outreach, optics education, didactic, science education, active learning, optics, education in developing countries
\end{abstract}

\section{INTRODUCTION}

Currently, in correspondence with the accelerated scientific and technological change, it is not only about how children learn Science as the only outcome pursued by the process of teaching it, indeed, it is clearly necessary to understand the role played by the learning of Sciences in the development of children in a broad context; Science is no longer a goal in itself, it has become a way for developing the potential of all students ${ }^{1}$.

It was timely and effective in this regard, the complaint that a publisher of the American Journal of Physics has made concern over the lack of teachers to stimulate interest in Science as a vehicle of culture ${ }^{2}$; besides, most of the teachers do not use the adequate strategies needed for students to accomplish the understanding of Science and its applications in life and technology, excluding the experimentation of their activities ${ }^{3}$.

This work describes the results obtained of the "O4K" Project, which was supported by the SPIE and the Universidad Autonoma de Nuevo Leon, where the didactic strategy of the integral formation of the students through the active learning of Physics was applied in the process of learning Optics of 1,600 kids of upper-elementary school. This strategy was stablish by the Dr. Juan Carlos Ruiz-Mendoza and it has been applied in different educational levels in public schools from Mexico (Fig. 1) where its feasibility has been ascertained ${ }^{4}$.

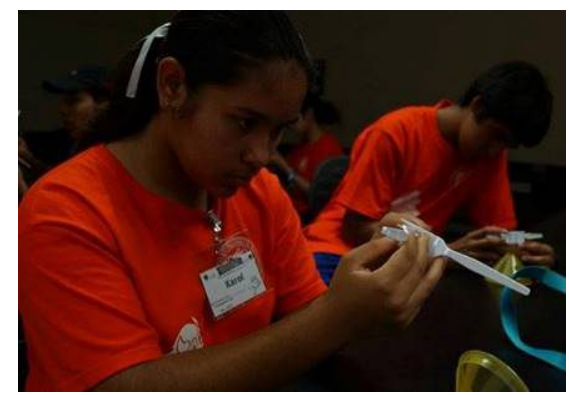

Figure 1. Elementary school students working in a class about classical mechanics where the didactic strategy of the integral formation through the active teaching of Physics was applied.

Optics Education and Outreach III, edited by G. Groot Gregory, Proc. of SPIE Vol. 9188,

91880P (C) 2014 SPIE · CCC code: 0277-786X/14/\$18 · doi: 10.1117/12.2058071 


\section{1 "O4K" Project}

The "O4K" Project was a research and outreach project composed by the following events:

- "Optics 4 Kids" outreach events organized by Univ. Autonoma de Nuevo Leon SPIE Student Chapter every year since 2011 in the facilities of its University (Figure 2).

- Workshop: "Optics 4 little bison" presented every year by the Univ. Autonoma de Nuevo Leon SPIE Student Chapter during the Summer Camp 'Little Bison' of the Facultad de Ciencias Fisico Matematicas of the UANL.

- "Optics Mobile" outreach events conducted by Univ. Autonoma de Nuevo Leon SPIE Student Chapter in local elementary schools since 2012.

- Workshops, courses and demonstrations performed by Dr. Juan Carlos Ruiz-Mendoza in public elementary schools since 2011.

This project was granted by the SPIE through the Chapter Activity Grants since 2011 and the Education Outreach Grant in 2013, likewise was supported by the Universidad Autonoma de Nuevo Leon. Making use of the resources provided by the two institutions was possible the purchase of the materials needed to perform active learning activities and the components required for the construction of Optics outreach devices. The activities and devices were designed using, in most of the cases, easy-access materials and were planned to be safe and interesting.

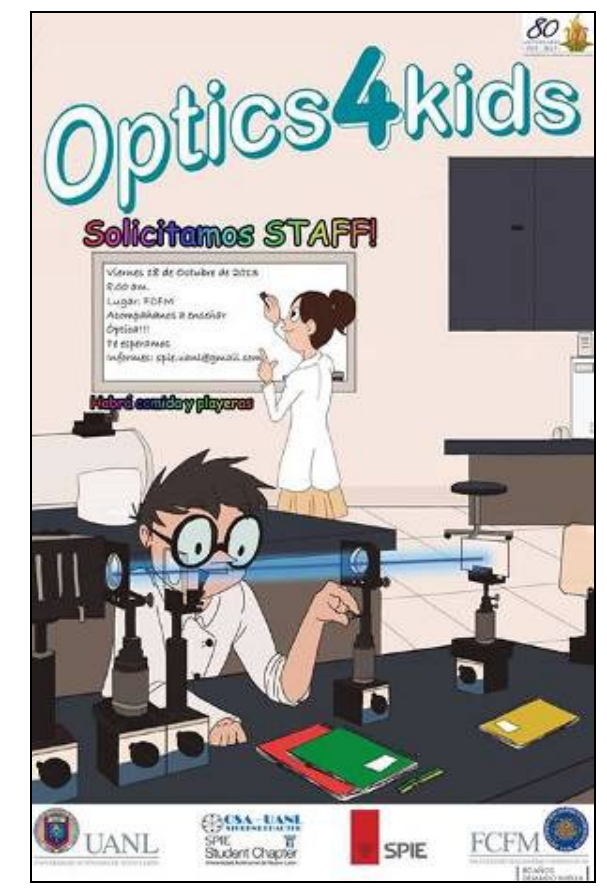

Figure 2. Advertising material used for involve undergraduate students as staff in the 'Optics 4 Kids' events.

The Table 1 contains the activities performed in the different events that compose the "O4K" Project by the UANL SPIE Student Chapter, the Dr. Juan Carlos Ruiz-Mendoza or both. Some activities underwent some slight variations thanks to the feedback received after finishing every event by students involved and their teachers. The activities listed in the Table 1 were the ones performed in all the events; however, each event was composed of 8 or 10 activities. At the end of the presentations, surveys were applied to children with the objective of obtain a feedback. 
Table 1. Representative activities for the "O4K project".

\begin{tabular}{|c|}
\hline ACTIVITY \\
\hline \hline Disc of Optics \\
Reflection law \\
Image formation in mirrors \\
Understanding waves \\
The human eye \\
\hline
\end{tabular}

\subsection{Teaching of Science en Mexico}

In Mexico, a lack in the use of an adequate didactic strategy for the teaching of Science exists, teachers generally do not make use of experimentation for link theory and concepts view in the classroom with the reality of our environment and the technological advance. Moreover, the amount of students in the areas of Exact or Natural Science is very low in comparison to other fields ${ }^{5,6}$.

\subsection{Strategy development}

The study plans in Natural and Exact Sciences in elementary school, designed by the Ministry of Education in Mexico, respond to a training that encourages the development of abilities and attitudes, because it leads to students to become interested in natural phenomena, learn to observe them and question them like what happens to them varying the conditions and what if the initial conditions are changed. The learning of Physics encourages students to develop their curiosity and to observe his surroundings as long as the conditions are appropriate.

According to the points above, it shows the need to propitiate a more comprehensive understanding of the teaching process of education and learning of science at the basic levels of education, so children through experimentation harmonize his general knowledge with his culture, where the cognitive and axiological are united. The achievement of this requires a different dynamic application that routinely develops for this process to transcend the limits of epistemological and contribute a more complete education of children ${ }^{7}$.

The strategy we propose is that through experimentation we motivate children and contribute to its formation according to the assumed concept of integral education as the process which children learn to know himself and the world around him, also, to transform the world and achieve self-transformation in the different fields and contexts of action expressed at an appropriate consistency between feeling, thinking, and acting ${ }^{8}$.

Therefore, we take into account that by observing, it is possible promote or increase the interest of the students for the analysis of natural phenomena and the interaction with their environment; it can also help them to achieve a better concentration, and also, it induces them to the implementation of an interpretive logic that integrates elements of discrimination, their interrelationships and functions from the perspective of complexity. The development of complex thinking in students as suggested by Morin ${ }^{9}$ goes beyond the search of structure of science, aims to link the order and disorder, beyond the need for differentiate the subject and object, uses a logic that links the separable and inseparable, far from the omnipotence of reason.

The link between theory and practice through experimentation provides students the opportunity to relate the abstract with the concrete, the objective with the subjective, internal and external. When the link is achieved, the reality is easier to understand. These aspects are closely related to creativity, in particular with the abstraction. The connection between theory and real life is something that is generally difficult to achieve, so this reflection reveals, "teachers and students have difficulty connecting theory with real life. Teachers themselves receive courses about different theories of teaching - learning and Physics courses, but have trouble applying those ideas in their classrooms"10.

Moreover, the experimentation as a key for teaching and learning optics method can be used not only for instructional purposes, but also as an enhancing method for education in positive values such as discipline, team work, honesty and with qualities as valuable as the will and perseverance, ergo an integral formation of the student. The Fig. 3 shows the basis of the didactic strategy of the integral formation of the students through the active learning of Physics, which indicates that the formation of the student through the process of teaching and learning of physics can be achieved when the conceptual and methodological instrumentation make possible a student development through mastery of his conceptions and methods, strategies and procedures for doing so, this conception is identified with the contemplation of 
the student as a subject and is against to the traditional way of teaching physics, were it develops the notion in this study $^{4}$.

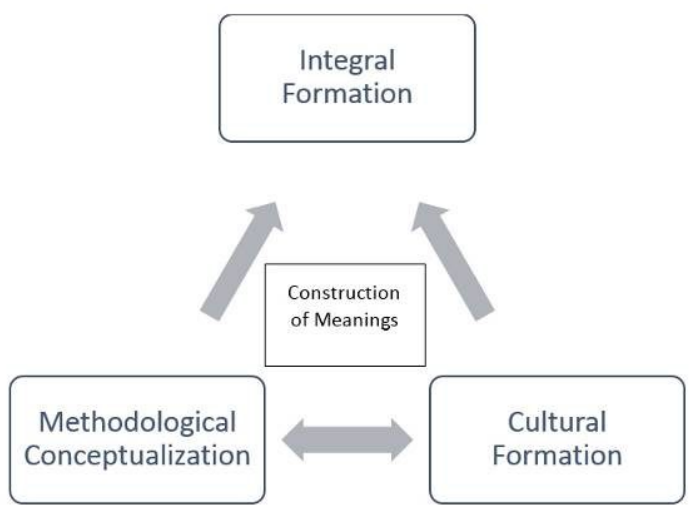

Figure 3. Scheme of didactic strategy that exposes the active learning of Physics as a methodology for the integral formation of the students ${ }^{4}$.

\subsection{The importance of learning Optics}

Optics is the main science that has enabled the humanity to obtain knowledge about the world that surrounds us and includes concepts and theories ranging from the interpretation of the nature of light to complex scientific and technological paradigms. In addition to this, the learning of Optics has been considered as a key factor for the development of the kids by UNESCO due to Optics is the "enabling Science" that it is believed to be the basis of many modern advances in high technology, considering this, UNESCO develops a special teaching method called "Active Learning of Optics and Photonics" that encourages the importance of learning Optics and represents a model for teacher training ${ }^{5,11}$. The results and success of this method have found that the teaching of optics contributes up to $80 \%$ with the teaching of Physics because Optics is the field of Physics that covers almost all the conceptions, laws and phenomena of Physics.

\section{IMPLEMENTATION OF THE INTEGRAL FORMATION STRATEGY IN THE LEARNING OF OPTICS}

Considering the importance of learning Optics for scientific and technological development of developing countries, during this project, we perform an adaptation of the teaching integral formation strategy to promote the interest of students in Optics and its learning, and, at the same time, looking to contribute with integral formation of the kids.

The next sections summarize the main activities of the project, describing how are designed and the concepts learned in each case. In addition, a section describing the feedback process.

\subsection{Disc of Optics}

At the begging of the project, the Optics Kit developed by Ruiz-Mendoza ${ }^{12}$ was used with the purpose of teach basic Geometric Optics, however, since it was designed for Optics education in High School, the components represented a non-safe alternative for the students due to the use of glass lenses and a bulb that generates high temperatures (Fig. 4). 


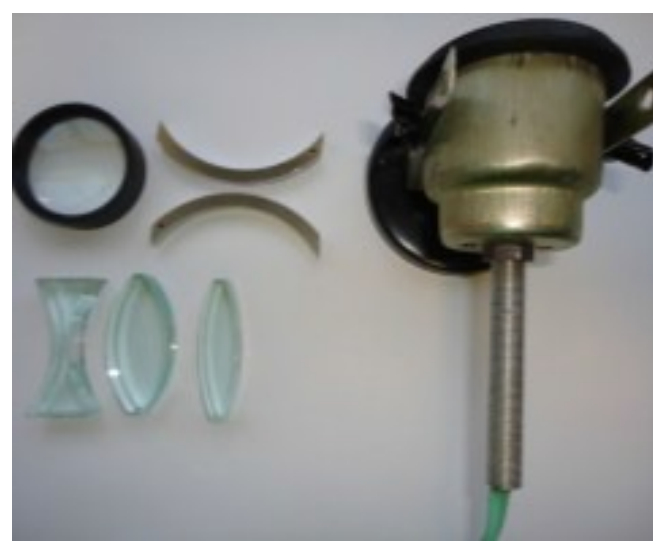

Figure 4. Some of the components of the Optics Kit (Ruiz-Mendoza) using at the begging of the project.

It was necessary make changes in the Kit, at the begging the glass lenses were substituted by acrylic lens designed by graduate Physics students of the UANL. Three red laser modules class I replaced the bulb, with a power lower than 5 $\mathrm{mW}$. At the end, a plastic rotating base was adapted to a wooden base homemade, creating with this a portable rotatable base where different lenses were mounted. This device was called "Disc of Optics" ("Disco de la Óptica" in Spanish) and represents the main tool for teaching Geometric Optics (Fig. 5).

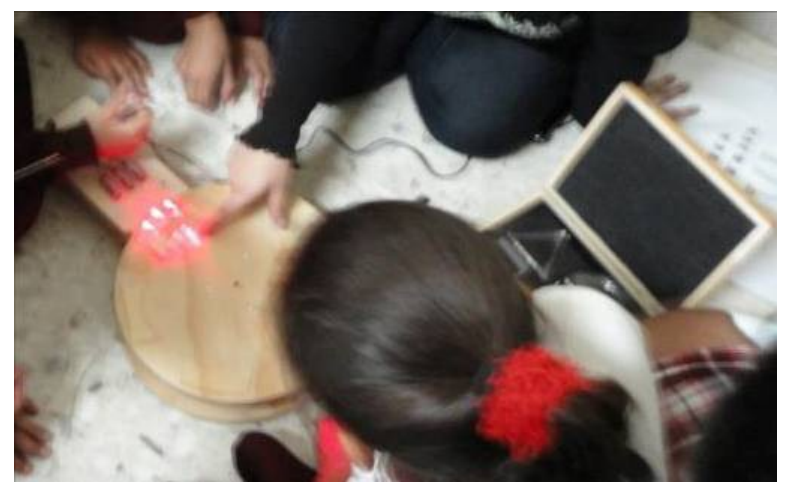

Figure 5. Disc of optics lenses used for teaching Geometric Optics.

The disc is used with a set of different lenses and mirrors that allows the construction of lens arrangement (Fig. 6). As the lens and mirrors are made of acrylic, the students could interact with them, feeling confident of its handle. In addition with the interaction, during the activity the kids learn the classification of the lenses, how interact a mirror in a lens arrangement and the application of lenses in several technological devices. 


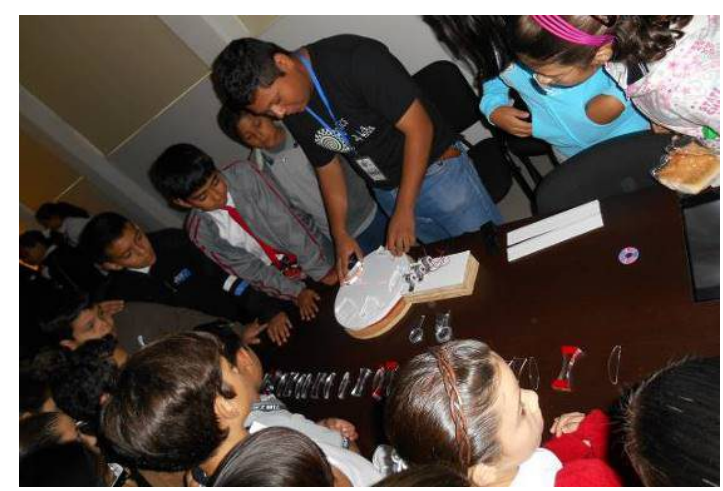

Figure 6. Kids using and learning with the disc of optics.

\subsection{Law of reflection}

Due to the detection of misconceptions in the understanding of the reflection of light, particularly in mirrors, the needed of an activity that allows the kids observe, analyze and prove the 'law of reflection' was founded; attending to that the 'classic' activity about reflection was implemented: the student uses a mirror where a light ray is pointed and, doing measurements proves the validation of the law; however the activity was not interest for some of the children and, in most of the cases, the kids does not related the measurements with the law of reflection (Fig. 7)

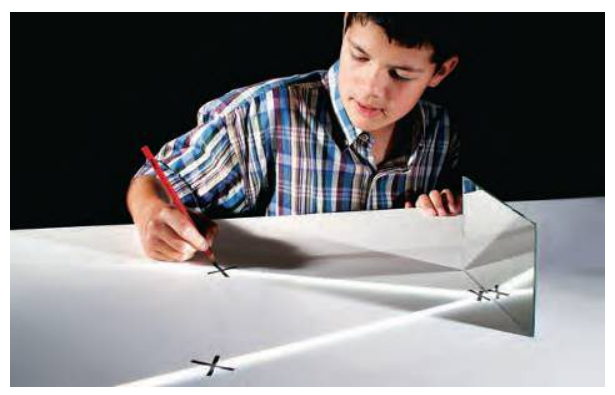

Figure 7. Light reflected into a mirror. Photo by Martyn F. Chillmaid(C Science Photo Library ${ }^{13}$.

Looking for a better activity that promotes the interest of the students and explains the law of reflection a new device was create: "The refection box". It is a box with top and bottom with a half circle shape made with foam board and acetate. It also has a vertical mirror and it is divided in 2 quadrants, the left one has signals from 0 to 80 degrees at intervals of 10 degrees measured from the border with the right quadrant, the right one has the same graduation but in each signal also has a window that allows look inside the box. In left quadrant, a pallet with a standing image, which can be moved and their angles are marked, is placed (Fig. 8).

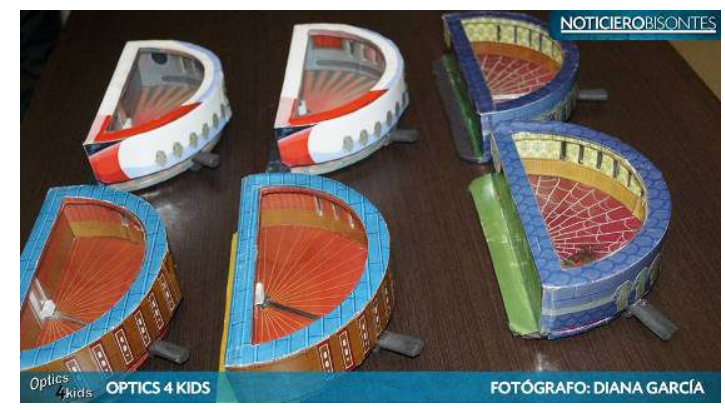

Figure 8. Reflection box create for teach the law of reflection. 
Using the reflection box, the students look through to each window and, in a specific window will find the image of the pallet, the next step is identify the degree of the window used for see the image and the degree where the pallet is placed, the process is repeated several times until the conclusion of the law of reflection in mirrors is formulated for the students (Fig. 9).

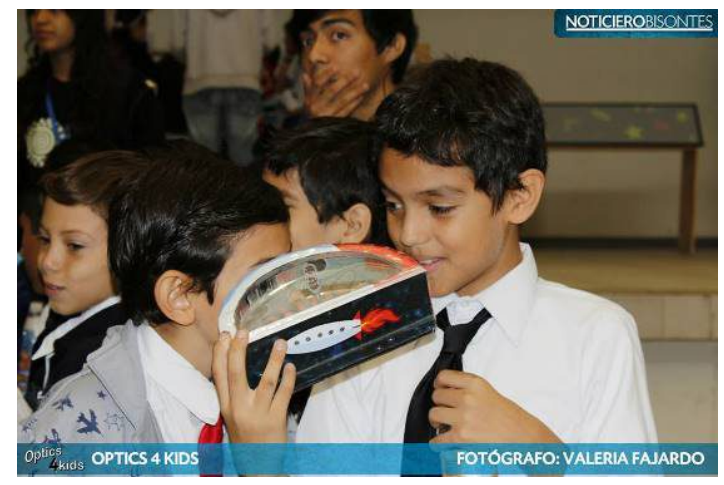

Figure 9. Kid explaining to a partner the function of the reflection box.

At the end of the activity, the students understand different applications of this law as magic tricks, periscopes, change the path of the light and others (Fig. 10). This version of the law of reflection activity keeps the attention and the curiosity of children because they do not know the function of the box.

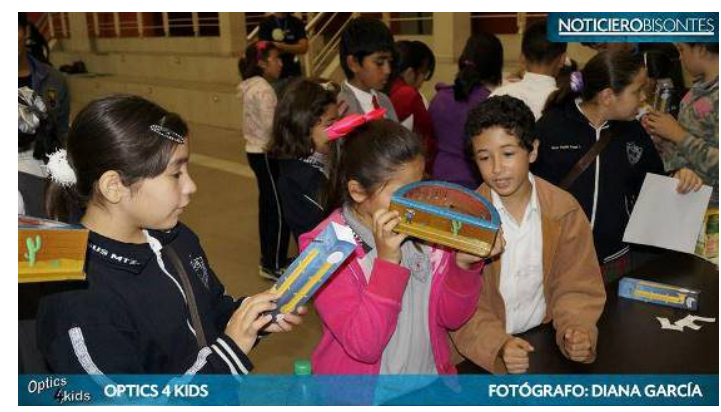

Figure 10. Group of children relating the law of reflection learned with the reflection box with how works the periscope.

\subsection{Image formation in plane mirrors}

For this device, semitransparent mirrors were purchased, to which they sanded the edges and they put a plastic protector. For the stand base, we use two homemade pieces of wood. Also for this activity, we need crayons and a piece of grid paper with an image in it and a line to place the mirror (Fig. 11). 


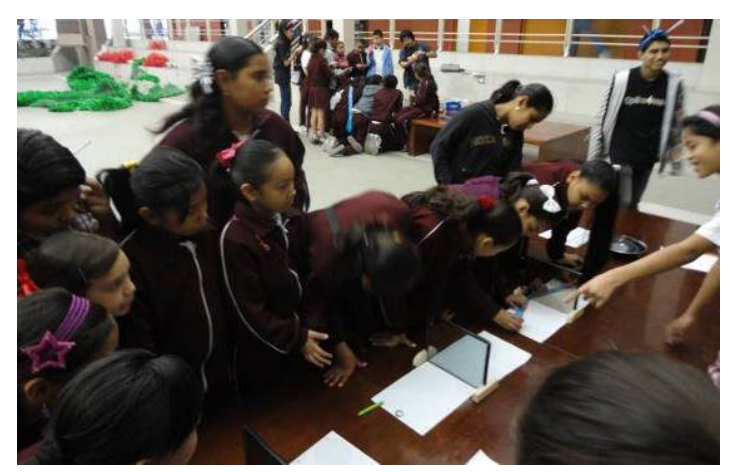

Figure 11. Kids listening the instructions for the 'image formation in plane mirrors' activity.

For the activity is needed a picture that will be placed in the paper between the kid and the mirror, later the kid will look through the mirror and will redraw the original picture. When the kid finish it is necessary that he/she measures the distance between the original picture and her/his draw using the grid of the paper. As conclusion, the kids learn the image formation in plain mirrors.

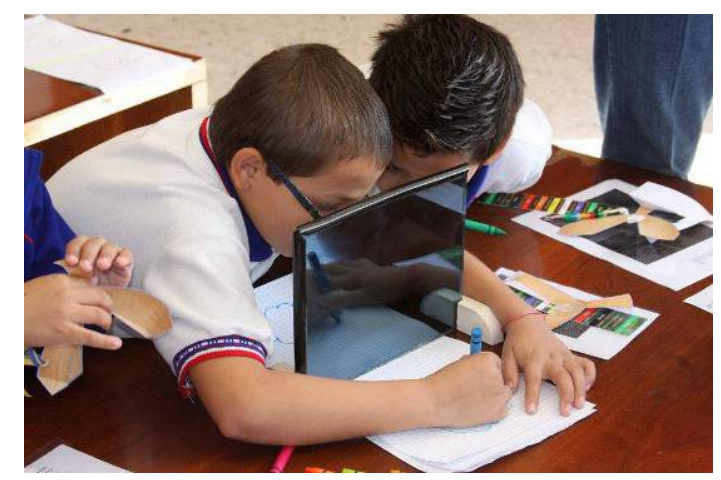

Figure 12. Two kids working together during the activity of image formation in plain mirrors.

\subsection{Understanding waves}

This activity contains three different experiments that allow a good understanding of waves. The first experiment use a device that has a rope tied to a small motor and in the axis is placed one wall plug with a screw in it to rotate the entire system when turning on. When you turn on the engine and tighten the rope just by dropping the motor, standing waves are generated in the rope (Fig. 13). With this is very simple understand the concepts related with waves as amplitude, crest, valley, wavelength and wave front. 


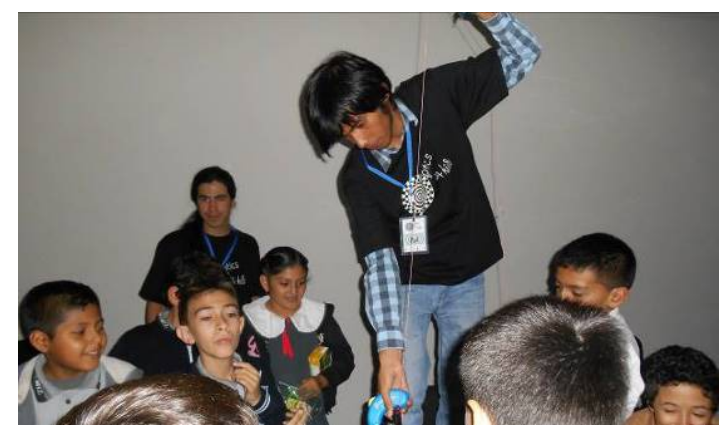

Figure 13. Children waiting for the begging of the activity with the wave motor.

The second experiment is the use of a slinky with the purpose of generate transverse and longitudinal waves. In addition, analyze again the waves concepts viewed before (Fig. 14).

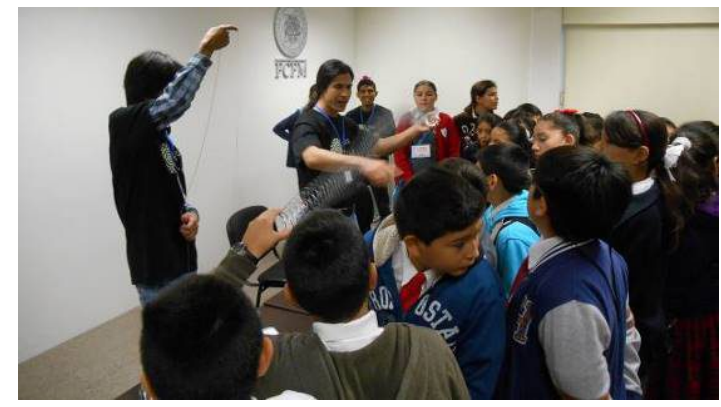

Figure 14. Children generating different types of waves.

At the end, the concept of frequency is studied using a stroboscopic light with tuning frequency and a rotating disc with a series of images that represent a sequence of movement. Whit these materials the kids are asked to change the frequency of the light and describes what she/he sees when the disc is rotating, when they are capable to see the sequence of movement like a picture with movement, they must continue changing the frequency and see the picture with movement but in reverse way. The definition of frequency must be teach by the person in charge of the activity but, with a series of questions, children are capable to understand the concept of frequency with confuses it with velocity and, also, must be able to explain what happen when 2 frequencies are matched (Fig. 15).

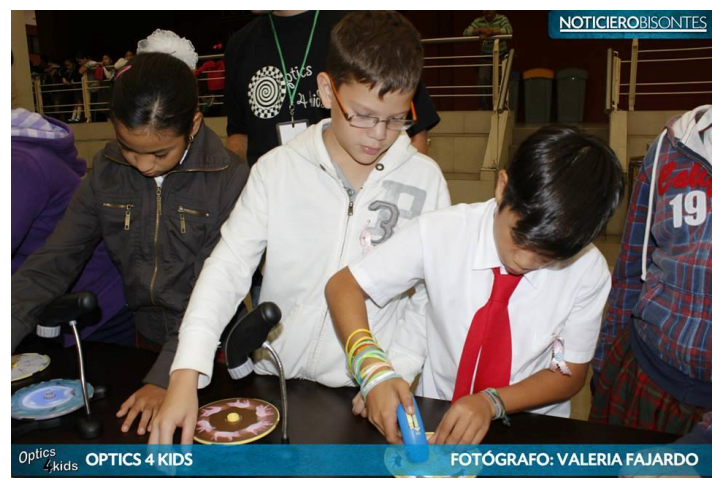

Figure 15. Kids playing with different frequencies of the lights. 


\subsection{The human eye}

This was the most complete activity done during the project; various devices are used: set of acrylic lens, anaglyph glasses and illusions of depth. The aim of this kit is to use different flat lenses to explain how the human eye works, and the visual problems: nearsightedness and farsightedness. At the same time is also used to explain the operation of the concave and convex mirrors, due to that is better if the kids make the activity with the Disc of Optics before and later, with this activity could understand the Geometric Optics applied in the human vision (Fig. 16).

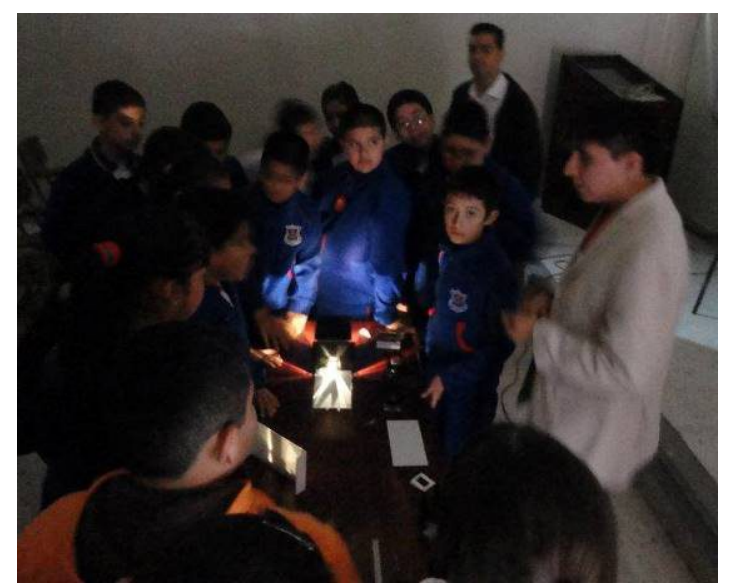

Figure 16. Kids learning about how the human vision works.

Also for this activity, anaglyph 3D glasses and images are used to teach the stereoscopic vision. Thus, show the importance of having a pair of eyes to our vision (Fig. 17).

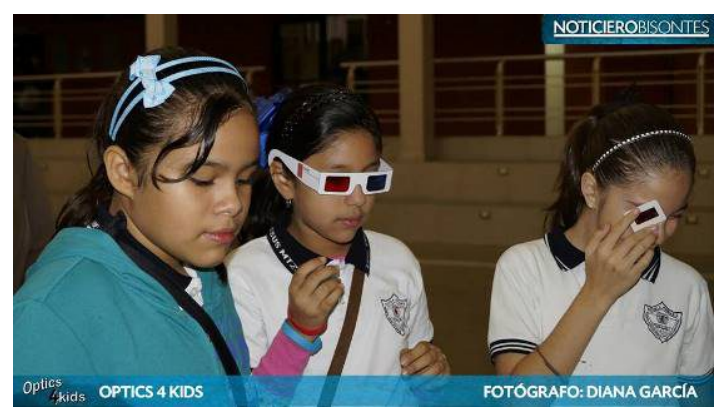

Figure 17. Group of girls analyzing the differences between the use of only one eye and both in the 3D effect.

At the same time, optical illusions of depth to understand an application of stereoscopic vision, complement all the learning of the human eye and explain that sometimes our brain create optical illusions. Another important part of this experiment is use a camera for see the illusion of depth, the kids will understand that the camera is also an optical system, as our eyes, but this one has only one lens (Fig. 18). 


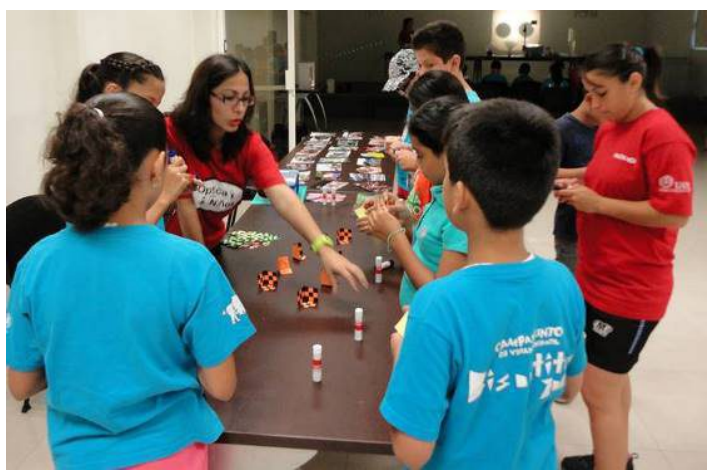

Figure 18. Children creating an optical illusion of depth.

\subsection{Design of surveys}

As a method of obtain feedback, simple surveys were designed where the questions were:

1. What was your favorite activity?

2. Did you learn something new today?

3. At least one of our experiments amuse you?

4. Do you like doing Science experiments?

5. Do you prefer working in teams or individually?

6. Would you like to participate in our activities again?

The answers were with a logic that surprised us and made us think that the proposed strategy can yield satisfactory results. In addition, with the surveys we identified others important factors for the development of the activities in a good way (Fig. 19). These results are shown in the next section.

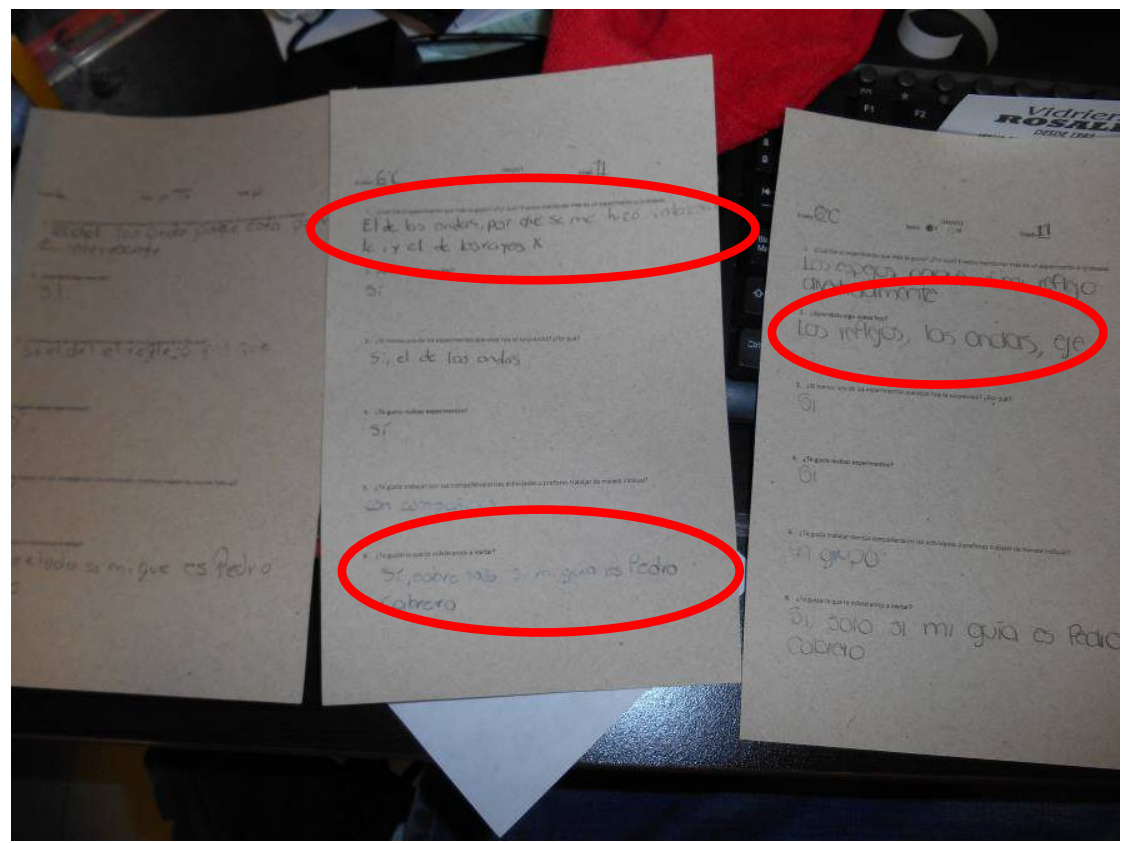

Figure 19. Surveys of the event "Optics 4 Kids 2013" where 230 student visited the facilities of the UANL and divided in groups driven by UANL students through different activities. 


\section{RESULTS}

During all the events of the "O4K" project, the children answered and interacted with us and with the experiments with a lot of confidence and with any fear to be wrong because they were aware that it was not a test and it was just an activity for the pleasure of building the experiment.

\subsection{Learning process}

The learning process, in most cases, was very fluent and even, some of the children were not conscious of what they learned during the day's activities until they are questioned about it.

In almost most of the cases, the kids said they learn something new, and they were surprised with the activities of waves (Fig. 19) and the human eye, because they considered that learn several things in these activities.

In addition, they talked about the knowledge acquired during the activities because for most of them was easy understand a concept when they can prove it.

Likewise, in some cases was difficult for them learn the correct term of the phenomena, but they learn and understand why and how happen.

Some kids had the capacity of find by themselves the application in their lives of the concepts shown.

\subsection{Interest in Science}

A big interest in Science was generated thanks of the activities; this interest was detected in different ways. At the end of each event a series of Physics demonstrations during 15 or 30 minutes were performed, and every time a volunteer was needed for an activity the interest of be part of the experiment was at least of the $50 \%$ of the kids (Fig. 20).
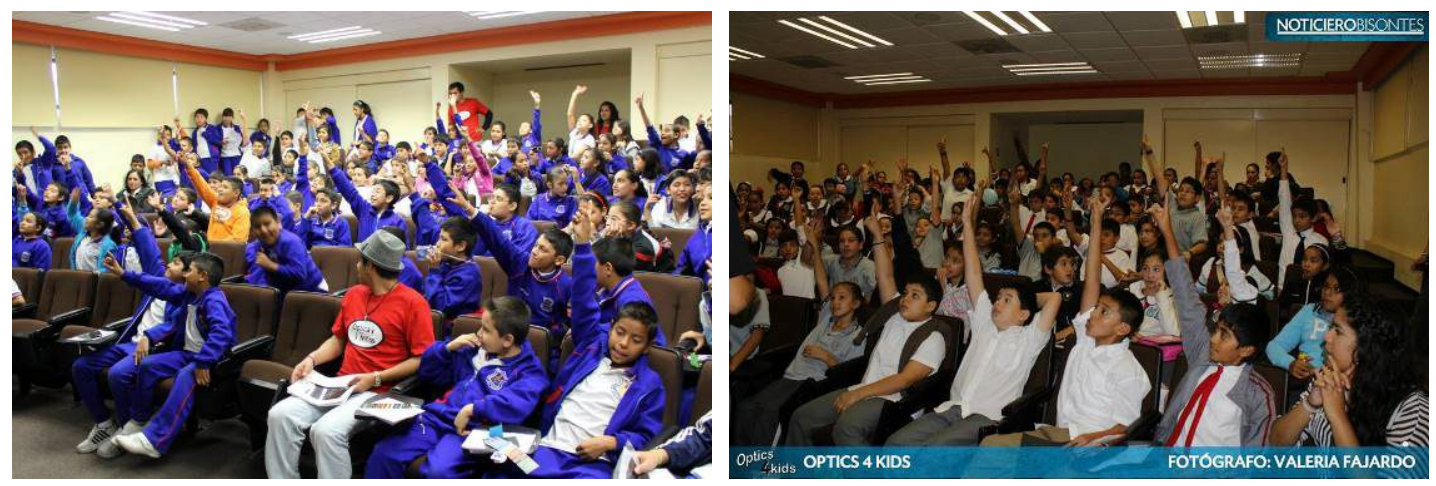

Figure 20. Participation of the kids during the Physic demonstrations at the end of the events.

In the surveys all the kids answering that they will participate in this kind of activities again. In fact, some schools are looking being part of these events again because the kids are very excited about Science experiments.

In addition, in the section of the survey about if something was amazing for them, we received interesting comments as:

- "... Yes, the experiments were fun and the wave experiment looks very cool..."

- “... Yes, I'm amused with the function of the eyes, I never thought that the lenses of my eyes work that way and I never imagined that my eyes see the world upside down..."

- “... Yes, the mirrors because I believed the reflection of the image was formed in the surface of the mirror..." 


\subsection{Integral formation}

All the persons involved in the activities detected important behaviors of children during activities:

- The collaboration work was the most notorious value saw during the activities, the students worked together with the purpose of find the answers about the experiments faster and the students explain to each other.

- During the brainstorming process generated by the questions done during the experiments the kids were respectful in almost all the cases. In addition, when one student had an inappropriate behavior his/her partners asked him/her have a good conduct.

- They applied the observation and the critical thinking during the experiments.

- Almost of the children improve their creativity and imagination looking for the answers at the phenomena exposed.

- Some kids develop skills as the formulation of hypothesis, capacity of abstraction. The first one trying to explain things they did not understand and, the second one, looking for applications in the technology and their lives of the optical phenomena studied.

\subsection{Other key factors}

The implementation of experiments for obtain the active learning of Optics was the main reason of the success of this project, but thanks of the surveys and the opinion shared by the kids we can find other important factors that help with the learning of Science, the increase in the interest in Science and the integral formation of the students:

- The behavior of the persons whom they interact during the different activities. The best examples of this were the "Optics 4 Kids" events where are bachelor students who help guiding the kids through the different activities. With the surveys we can see that the kids feel more confident, interested and with a lot of energy when this 'guides' are people trying to establish an empathetic relationship.

- The 'envelope' of the experiments, in other words, if the devices are full of color, use bright lights, look though and safe then these could promote their curiosity. In the case of the activities is easier for them in we use lasers, bright led or jokes with the objective of catch their attention.

- The existence of no wrong answers.

- The capacity of instinctive interaction with the devices, because for them all the materials presented were easy to handle.

The general result is that the "O4K" project was very successful and it is very important continue with it.

\section{CONCLUSIONS}

The results obtained through the implementation of the strategy shown that children understood the concepts covered on the topics of Optics. In addition, they reflected and exchanged with peers about these experiments.

With the use of this teaching strategy students shows a highly motivated attitude for the understanding of this part of Physics, the opinion criteria were favorable in general. Showed interest to build their periscopes and expressed that in the future they would like to study the optics science.

\section{AKNOWLEDGMENTS}

This project was granted by the International Society for Optics and Photonics and the Universidad Autonoma de Nuevo Leon through the Facultad de Ciencias Fisico Matematicas.

Also, it was supported by the Academic Group 'Photonics and Telecommunications' of the Centro de Investigacion en Ciencias Fisico Matematicas lead by the Ph. D. Romeo Selvas-Aguilar.

Thanks to "Noticiero Bisontes", the Facebook's newspaper of the Facultad de Ciencias Fisico Matematicas, they have covered the last events and helped taking pictures. 
Thanks to Dr. Daniel Ceballos (Fig. 16) for his support and ideas in different experiments and events during the project.

The construction of the project was possible thanks of the expertise and support of the Dr. Juan Carlos RuizMendoza.

\section{REFERENCES}

[1] Ruiz, J., "Alternativa metodológica para la formación integral de los estudiantes desde el proceso de enseñanzaaprendizaje de la Física," Doctoral Thesis, (2005).

[2] Whitaker, R., "Aristotle is not dead: student understanding of trajectory motion," American Journal of Physics 51, 352-357 (1983).

[3] Vergara, D., "Estudio del impacto didáctico de la metodología De aprendizaje activo en la enseñanza de la óptica," Master Thesis, (2012).

[4] Ruiz, J., "Alternative methodology for the training of students from the teaching-learning process of physics," Report doctoral thesis in Education, 34. Universidad de Camagüey, Cuba, (2006).

[5] Alarcon, M. et al, "Active learning in optics and photonics (ALOP): a model for teacher training and professional development," Proc. SPIE 7783, 778-303 (2010).

[6] Agencia de Noticias UN, "Con la óptica se mejora enseñanza de la física hasta un 80\%," Agencia de Noticias UN, 13 December 2010, http://www.agenciadenoticias.unal.edu.co/detalle/article/con-la-optica-se-mejora-ensenanza-dela-fisica-hasta-un-80/ (27 January 2014).

[7] Ruiz, J., "Estrategia didáctica para la formación integral del estudiante de bachillerato mediante el proceso de enseñanza-aprendizaje de la Física," Revista Iberoamericana de Educación 40 (2), 1681-5653 (2006).

[8] Torres, A., "Estrategia educativa para la autransformación integral del estudiante universitario," Ph. D. Thesis (2006).

[9] Morin, E., [Ciencia con conciencia], Anthropos, Barcelona (1984).

[10] Riveros, H., "¿Quiero mejorar mis clases de Física?," Instituto de Física de la UNAM, 3 (2003).

[11] González, C., "La enseñanza de la óptica desde una conceptualización integradora de sus teorías, dinamizada y orientada por una concepción del Aprendizaje significativo crítico," Master Thesis, (2013).

[12] Ruiz, J. et al, "Alternativa para la formación del estudiante mediante el proceso didáctico de la Física en el Nivel Medio Superior," Revista de Investigación Educativa 10, 1870-5308 (2010).

[13] SEP, [Ciencias Naturales para el cuarto grado de educación primaria], Comisión Nacional de Libros de Texto Gratuitos, México, 103 (2011). 